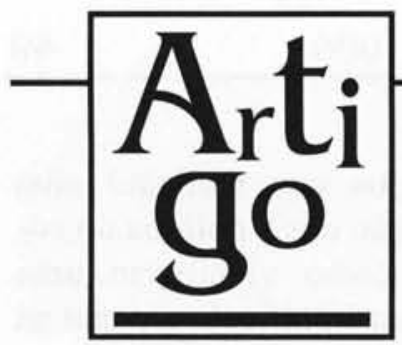

internacional

\title{
TRANSMISSÃO EDUCATIVA
}

E DESENVOLVIMENTO

\begin{abstract}
Esta é a terceira e última parte do artigo Transmissão Educativa ${ }^{1}$, levantamento monográfico realizado pela revista Tendências da Pesquisa de Comunicação, do Centro para o Estudo da Comunicação e Cultura da Universidade de St. Louis, EUA, que publicamos com exclusividade para os leitores brasileiros.

$O$ artigo discute a educação a distância do ponto de vista do desenvolvimento; quais objetivos, estratégias e recursos devem ser mobilizados para elevar o nível de conhecimento das populações mais carentes.
\end{abstract}

A Transmissão Educativa para o Desenvolvimento é geralmente proposta como meio de difundir, através de programas educativos utilizando diferentes tipos de mídia, métodos e técnicas para a melhoria da produção agrícola, práticas de higiene, saúde e planejamento familiar às populações carentes dos países em estágios menos avançados de desenvolvimento socioeconômico, predominantemente rurais, com alto grau de analfabetismo e deficiente infraestrutura.

\section{OS AUTORES}

Robert A. White

Pradip Thomas

Editores
Sistemas de Extensão Rural

Nas décadas de 50 e 60 , quando as primeiras orientações significativas de Transmissão para o Desenvolvimento começaram, o sistema de comunicação para as áreas rurais era estruturado em torno de funcionários da agricultura, saúde e outros tipos de "agentes de extensão". Todos supervisionados por uma estrutura governamental burocrática e hierarquizada em escritórios nacionais, regionais e distritais. A maioria destes sistemas de comunicação foram desenvolvidos nos Estados Unidos e Europa, de acordo com os serviços de consultoria rural, os quais entravam em contato pessoal com aqueles agricultores que estavam interessados em novas técnicas. $\mathrm{O}$ rádio foi utilizado para a transmissão de pro-

1. Para conhecer a primeira e a segunda partes ver, respectivamente, os artigos: Ensino a distância: experiências e inovações. Comunicação \& Educação. São Paulo: CCA/ECA-USP; Moderna, Ano I, n 3, p. 47-56, mai./ago. 1995. As múltiplas estratégias do ensino a distância. Comunicação \& Educação. São Paulo: CCA/ECA-USP; Moderna, Ano II, n 4, p.58-67, set./dez.1995. 
gramas que tratavam de métodos agrícolas para os homens e de assuntos domésticos para as mulheres. Tal modelo de transmissão também foi introduzido, como parte subsidiária dos sistemas de extensão, em países em desenvolvimento.

Como McAnany ${ }^{2}$ e outros estudiosos apontaram, o uso da transmissão para sistemas de extensão era geralmente ineficiente. Os produtores dos programas eram, na maioria das vezes, professores de agronomia ou saúde vindos de grandes cidades e, literalmente, liam no microfone lições de manuais, nos quais se utilizava uma linguagem técnica, seca e ininteligível para a população rural. Mais importante, agricultores mais humildes freqüentemente não tinham os recursos naturais ou o acesso aos mercados que as novas informações pressupunham. Ao longo dos anos, a transmissão de programas alternativos, dirigidos a estes grupos rurais, mostrou-se mais eficiente.

\section{Grupos de estudo pelo rádio}

Os grupos de estudo pelo rádio reúnem homens e mulheres agricultores de uma mesma comunidade para, primeiro, escutar atentamente uma transmissão dirigida aos grupos organizados e previamente conhecidos, para depois discutir como aplicar as práticas recomendadas com a supervisão de um líder da comunidade local.

Os grupos de estudo geralmente têm interesse por um assunto em particular. Este interesse deve ser discutido, de preferência, durante o processo de implementação. As transmissões começam com as perguntas dos agricultores sobre o processo, e os conteúdos se desenvolvem seguindo o ciclo natural das plantações.
O líder do grupo é geralmente um agricultor local que consegue "traduzir" a linguagem, mais técnica, das transmissões para uma linguagem acessível. Ele também responde às dúvidas do grupo, dirigindo a discussão sobre como uma nova prática pode ser integrada aos sistemas locais de cultivo, os quais, geralmente, têm equilíbrio precário, tendo sido adaptados ao solo, clima e outras condições locais por gerações seguidas de antepassados.

A discussão em grupo tem a vantagem de uniformizar a informação para todos os seus componentes, estabelecendo, assim, uma comunicação horizontal entre os mesmos.

Os grupos de estudo pelo rádio também utilizam outros meios como desenhos, pinturas, panfletos e audiovisuais simples. Os agricultores são encorajados a ter um local de demonstração nos arredores onde eles possam experimentar as novas práticas, antes de introduzi-las nos seus próprios sistemas produtivos.

Os líderes de grupo se encontram com frequiência com os supervisores locais apresentando-lhes as questões típicas e os problemas que surgem nos grupos de discussão. Estas questões formam a base das futuras transmissões. A programação relata atividades dos grupos, apresenta entrevistas ao vivo e tenta desenvolver um relacionamento quase pessoal entre os apresentadores e os agricultores.

\section{Transmissão de campanhas}

Um dos mais consistentes achados da pesquisa de audiência é que as pessoas ten- 
dem a adquirir e aplicar com mais ênfase as informações dos meios de comunicação de massa quando há um problema ou uma crise que gera a necessidade da busca de informações fora das fontes imediatas. Daí a importância das campanhas que são desenvolvidas para responder a situações de emergência como epidemias, orientação para grandes decisões nacionais, ou sobre o uso de uma nova tecnologia. As campanhas são geralmente orientadas para uma ação bem concreta com objetivos imediatos a curto prazo. Elas se concentram em chamar a atenção através de anúncios freqüentes, chamadas de apoio introduzidas durante toda a programação, depoimentos tanto de personalidades bem conhecidas quanto de pessoas comuns, slogans cuidadosamente elaborados etc.

As campanhas são multimídia, com pôsteres, cartazes, anúncios em outros meios, distribuição de folhetos e, principalmente, o engajamento de redes interpessoais numa grande variedade de organizações locais.

A maioria das campanhas são dirigidas a grupos de discussão locais, especialmente organizados, e a outros grupos já existentes. As campanhas exigem coordenação e apoio de várias organizações. Muitas delas introduzem um toque pessoal com a transmissão de visitas a comunidades locais, debates sobre as vantagens e dificuldades que as pessoas encontram na compreensão das campanhas, demonstração de bons resultados alcançados por outros membros da comunidade etc ${ }^{3}$.

Um dos casos mais amplamente citados nessa área refere-se a uma série de campanhas de desenvolvimento lançada na
Tanzânia, na década de 70, e mencionada por Bates, por Jamison e McAnany. Foi uma campanha feita em 1973 para introduzir melhores práticas de saúde e envolveu cerca de 75 mil grupos de discussão locais, com mais de 2 milhões de adultos participantes. As avaliações mostraram um crescimento de $47 \%$ no conhecimento e ampla adoção de práticas preventivas de saúde, tais como construção de latrinas, limpeza de áreas de proliferação de insetos e a fervura da água a ser consumida. As rádios escolares na América Latina também desenvolveram formas de campanhas pelo rádio, particularmente apropriadas para o seu contexto cultural.

\section{Entretenimento}

Uma das falácias mais amplamente difundidas nas primeiras tentativas de se usar a Transmissão para o Desenvolvimento foi a idéia de que, se a informação fosse apresentada de maneira clara e séria, os ouvintes seriam convencidos de suas vantagens "óbvias", através de argumentos racionais. Produtores foram recrutados entre professores, agrônomos, tecnicamente treinados, e burocratas do governo - pessoas que geralmente se caracterizavam por um estilo pesado, didático e autoritário.

Os responsáveis pela comunicação para o desenvolvimento percebem, hoje, que as transmissões devem usar dramatizações, humor, um ritmo rápido e um toque pessoal. Na América Latina alguns dos programas educativos mais eficientes estão usando o formato dramático da radionovela e da telenovela.

3. CABEZAS, Antônio e ROSARIO, Amable. La Emisora Regional para el Desarrollo. (Emissora Regional para o Desenvolvimento) Hilversum, Holanda, e Quito, Equador: Projeto Rádio Holanda em CIESPAL, 1980. 
Um caso de programa educativo que adotou o formato de "show de variedades" é a transmissão diária de Universidade para Todos da Rádio Santa Maria ${ }^{4}$, na República Dominicana, realizada há mais de quinze anos. A Universidade para Todos conquistou uma leal audiência que, estima-se, varia de 300 mil a 500 mil na região centro-norte da República Dominicana. O programa é centrado em torno de um apresentador e de uma apresentadora. Eles mantêm um clima amigável, enquanto introduzem uma breve dramatização nos moldes da radionovela, seguida por discussões sobre o assunto no estúdio. Isso é intercalado com cartas dos ouvintes (muitas vezes denunciando o mau atendimento público), anúncios de atividades de organizações, promoção de campanhas e conselhos para agricultores e donas-de-casa. Uma parte do programa particularmente interessante tem sido a dramatização na comunidade. Os apresentadores vão para uma comunidade na região, conversam com as pessoas sobre suas atividades e seus problemas e, então, pedem para que elas façam uma dramatização de um tema comunitário. A dramatização e um subseqüente debate são gravados e editados para a transmissão. Os apresentadores solicitam cartas dos ouvintes com comentários sobre $\mathrm{o}$ programa e recebem convites para visitar outras comunidades. O programa, portanto, fornece um tipo de diálogo inter-comunitário.

\section{SATÉLITES NA EDUCAÇÃo}

Uma pesquisa de avaliação de projetos de comunicação via satélite encontra gran- des dificuldades devido à natureza complexa de cada um deles, como aponta um estudo do Projeto Share 5 . O sucesso ou fracasso de um dado experimento geralmente leva anos para ser determinado com qualquer grau de confiança. Ainda assim, o critério de "sucesso" ou "fracasso" pode não ser o mesmo entre todos os observadores. O estudo cita, por exemplo, um link (ligação, conexão) de televisão ao vivo no qual uma universidade, em Dublin, transmitia aulas regulares para estudantes na Universidade de Amã, na Jordânia, duas vezes por mês, por vários meses, via satélite. Apesar de o projeto ter sido extremamente popular em ambas as instituições e altamente "satisfatório", o estudo sugere que muito poderia ser feito para baixar o seu custo se, simplesmente, fossem enviadas fitas de vídeo para a Jordânia por avião, ao invés de usar o oneroso link de satélite. Por outro lado, a conexão ao vivo, via satélite, adicionou uma certa excitação que provavelmente mostrou seu valor como um instrumento educacional. Seria difícil dizer se este estímulo valeu ou não o custo extra.

De acordo com o estudo de Bates ${ }^{6}$ para o Secretariado da Comunidade Britânica, os satélites são, em muitos países, um meio flexível para se conseguir serviços educativos valiosos. Bates verificou que vinte países estavam usando ou estavam conectados a satélites com propósitos educacionais. Estes países incluíam desde Austrália, Canadá e Índia até pequenas ilhas como Granada, no Caribe e Vanuatu, no Pacífico.

4. CABEZAS, Antônio et al. La Emisora Popular.(A emissora popular) Hilversum, Holanda: Centro de Treinamento da Rádio Holanda, 1982.

5. PROJECT SHARE: Satellites for Health and Rural Education.(Projeto Share: Satélites para saúde e educação rural) London: International Institute of Communications, 1986

6. BATES, Anthony W. Satellites for Commonwealth Education: some policy issues - A Study Commissioned by the Commonwealth Secretariat. (Satélites para a Educação da Comunidade Britânica: algumas questões políticas - Um estudo comissionado pelo Secretariado da Comunidade Britânica) Milton Keynes,UK (Reino Unido), (manuscrito), 1987. 
Os satélites são especialmente úteis na transmissão de programas educativos a longas distâncias, pois são um meio eficaz de se alcançar regiões remotas ou isoladas. Eles também foram considerados úteis no envio de novos serviços que não podem ou não poderiam ser enviados por transmissão terrestre.

O relatório de Bates é baseado no estudo de cinco casos de experiências na Austrália (projetos educacionais utilizando o AUSSAT), Canadá (A Rede do Conhecimento que usa o satélite Anik-C), Índia (projetos educacionais com o INSAT), Pacífico Sul (A Universidade do Pacífico Sul possui a USPNET ${ }^{7}$ que utiliza o sistema INTELSAT), e as Índias Ocidentais (Projeto de Ensino a Distância da Universidade das Índias Ocidentais, que também usa o INTELSAT).

Os serviços educacionais do AUSSAT, na Austrália, variam de programas educativos gerais a programas de ensino específico, voltados para crianças em áreas isoladas, utilizando um misto de TV, rádio e telefone. A responsabilidade pelos programas foi dividida entre governo, companhias privadas e instituições de ensino. Um exemplo de uso específico do AUSSAT é dado por Duke $^{8}$ que cita a Escola do $\mathrm{Ar}$ de Queensland, a qual utiliza o satélite para viabilizar uma ligação interativa entre crianças localizadas em áreas isoladas e professores especialistas, num estúdio em Brisbane.
A Rede do Conhecimento do Canadá9, discutida anteriormente, é uma rede de TV educativa financiada pelo Governo da Província de British Columbia. Os programas são transmitidos através do satélite Anik-C tanto para receptores comuns quanto para sistemas a cabo. Dukes relata que um consórcio de Universidades Livres se desenvolveu, ocasionando crescimento das atividades de ensino a distância. Cerca de 100 horas semanais são transmitidas regularmente, de várias fontes, na Rede.

As primeiras experiências na Índia com o uso de satélites na educação começaram em 1975, usando o satélite americano ATS-6. Naquela oportunidade, os programas de TV do Projeto de Televisão Educativa Via Satélite (SITE) foram transmitidos para mais de duas mil vilas. Mais recentemente, o governo indiano elaborou e construiu o satélite INSAT 1B. Ele fornece, para as escolas, programas educativos de desenvolvimento rural e de educação de nível superior.

Duke conta que há cerca de quatro horas de programação por dia na rede indiana. A maioria das vilas possui uma malha simples, de três metros e meio, para receber os sinais. Cada comunidade local recebe "treinamento" para utilizar o serviço. Programas especialmente preparados são produzidos pelo Instituto Central de Tecnologia para a Educação, em Delhi, e por outras instituições nos Estados.

7. A sigla USPNET - University South Pacific's Networld - sistema de educação a distância que utiliza o satélite INTELSAT, não tem nenhuma relação, além da casual semelhança, com os serviços da USPnet - Universidade de São Paulo interligada à rede Internet. (N.E.)

8. DUKE, John. Olympus in perspective.In:Proceedings of the Seminar and Workshop on the ESA Olympus Satellite for Education and Training in Europe. (Olympus em perspectiva. In:Procedimentos do Seminário e Workshop da Agência Espacial Européia Satélite Olympus para educação e treinamento na Europa). Avignon: França, 13-15 abril, 1988. Paris: European Space Agency, 1988, p.1-11.

9. Ver artigo: As múltiplas estratégias do ensino a distância.Comunicação \& Educação. São Paulo: CCA/ECA-USP; Moderna, Ano II, n 4 , p.58-67, set./dez. 1995. 
Onze países no Pacífico são servidos pela Universidade do Pacífico Sul. O campus principal é em Suva, Fiji, e possui extensões em outras ilhas. Utilizando o INTELSAT, assim como o rádio e linhas terrestres de telefone, os cursos são fornecidos aos alunos com áudio-aulas interativas, com a oportunidade de os estudantes questionarem e discutirem o material com os professores.

A Universidade das Índias Ocidentais fornece um serviço similar para centros em diferentes países do Caribe. Como a USPNET, ela utiliza o INTELSAT e sinais de telefone, rádio e microondas.

Bates conclui que é essencial para os professores e produtores educacionais estarem envolvidos no planejamento e elaboração de projetos educacionais via satélite desde o início. Os projetos, via satélite, devem ser tratados como parte de todo um sistema educacional, assim como muitas outras tecnologias - do rádio, TV a cabo e telefone a materiais impressos $\mathrm{e}$ fitas cassetes - devem ser envolvidas.

Outra importante conclusão é que a principal utilização dos satélites, em países em desenvolvimento, deve ser através da audioconferência. Isso permite um diálogo de alto nível e é muito mais barato produzir e transmitir do que veicular em emissoras. Entretanto, como a audioconferência tende a ser limitada a uma parcela reduzida de localidades, não alcança o grande número de telespectadores que a emissora pode servir.

Bates também acredita que os países em desenvolvimento podem considerar a utilização dos satélites para correio eletrônico e transferência de textos. Por causa do seu alto custo, a televisão deveria ser usada apenas quando uma produção e recepção adequadas fossem disponíveis.
Se a televisão for usada, a prioridade deve ser dada, sempre que possível, a programas locais.

As últimas recomendações do relatório de Bates apontam que deva ser feito um estudo para avalizar a possibilidade de se estabelecer uma rede de comunicação interinstitucional para a educação.

\section{Projeto Share}

O Projeto Share foi inaugurado em janeiro de 1985 pelo consórcio internacional de satélite INTELSAT e o Instituto Internacional de Comunicações. A idéia era de que, num período de três anos, o uso gratuito da rede internacional do INTELSAT iria ajudar projetos na área de saúde e educação em longas distâncias.

Os projetos, de acordo com Duke, incluíam experiências com videoconferências, transmissão de aulas pela TV e intercâmbio de dados.

O Projeto Share, que terminou em 1988, foi seguido pelo Projeto Acesso, que pretende veicular programas de desenvolvimento da saúde e da educação.

O relatório IIC sobre o Projeto Share concluiu que os projetos que obtiveram maior sucesso foram aqueles que envolveram as tecnologias mais simples. Os projetos que utilizaram equipamentos caros e extensivos planejamentos, tais como aqueles que envolveram transmissões de TV como principal meio, geralmente acabaram assim que terminou o Projeto Share.

O relatório IIC, assim como o de Bates, enfatiza as possibilidades abertas pelos satélites para uma genuína comunicação de duas vias. 


\section{Olympus}

Em julho de 1989, a Agência Espacial Européia (ESA) lançou um satélite de comunicação chamado Olympus. Este foi o segundo satélite experimental lançado pela ESA. O primeiro, em 1979, foi um satélite experimental comercial que levou a toda uma geração de satélites comerciais. O planejamento do Olympus começou imediatamente após aquele lançamento, e foi possível tirar proveito da experiência da transmissão comercial via satélite.

Dos dois canais diretos de transmissão do satélite, um foi usado pela rede italiana RAI para transmissão direta para os lares italianos. E o outro esteve disponível para serviços de transmissão direta para a Europa Ocidental e partes do Leste europeu. Seu uso ficou limitado a serviços científicos e públicos. Seus horários de pico foram usados como canal de serviço público para toda a Europa.

O tempo remanescente estava disponível para usuários que veiculavam programas educativos e outros. Eles fundaram uma organização denominada Fundação Eurostep. Através desta Fundação negociavam com a Agência Espacial Européia. A Eurostep tem membros tais como a Rede Ecumênica Olympus (EON), um grupo de indivíduos ligados à igreja de diferentes países da Europa, que asseguraram 25 horas por ano para a transmissão de programas de ensino religioso. Os membros da EON exploraram continuamente as possibilidades de utilização efetiva do tempo que tinham disponível.

\section{Canal E}

O Instituto Europeu de Mídia (EIM) e três organizações associadas pla- nejaram, em 1989, uma série experimental de programas educacionais e de treinamento, utilizando o satélite comercial ASTRA. As primeiras 104 horas de programação pretenderam identificar os usuários potenciais e servir como estudo piloto para um possível serviço permanente europeu de televisão educativa e de treinamento via satélite.

\section{TRANSMISSÃO PARA MUDANÇAS SOCIOPOLÍTICAS}

Muitas pessoas que trabalham e estudam a Transmissão para o Desenvolvimento estão cientes de que a maioria dos métodos comuns como serviços de extensão, grupos de estudo pelo rádio etc. não toca nas causas mais fundamentais da pobreza rural.

A tão conhecida "Revolução Verde" é geralmente citada como um caso de sucesso na comunicação de informações técnicas. Na verdade, na Índia, ela gerou um crescimento da pobreza $e$ desemprego, porque centralizou as informações nas elites rurais, fazendo os ricos ficarem mais ricos, enquanto os pobres ficaram impossibilitados de tirar vantagens dela.

Desse ponto de vista, o problema central é que a maioria dos programas convencionais para o Desenvolvimento não estão baseados em uma análise de como as estruturas de poder local controlam os canais de informação e as definem de acordo com os seus próprios interesses. Dada tais críticas muitos dizem que a prioridade é um tipo de comunicação que ajude os mais pobres a formar uma base de poder independente e organiza- 
da, e uma rede de comunicação alternativa controlada por eles próprios ${ }^{10}$.

Muitos movimentos sociais populares sentiram que a Transmissão era um meio muito "visível" e vulnerável ao controle das elites, o que os levou a preferir trabalhar com formas de mídia pequenas, "controladas pelo povo", tais como a mídia de grupo, imprensa alternativa e teatro popular. Além disso, em muitas partes do mundo, como Índia e África, é a Transmissão que protege os governos centrais, que são controlados pelas elites. Uma exceção é a América Latina, onde a maioria dos países dão concessões de emissoras a grupos privados sob regulamentação do governo.

Bates, Jamison e McAnany citam o caso das estações de rádio da Igreja Católica, na América Latina, como um exemplo do uso da Transmissão para uma maior consciência sociopolítica, ajudando os mais carentes a formarem uma base de poder organizada e independente ${ }^{11}$.

Desde a década de 50 a Igreja Católica tem feito uma grande mobilização de pessoal e recursos para o ensino não-formal e para organizações de carentes rurais e urbanos, especialmente onde os serviços governamentais são escassos. A posição oficial de bispos católicos na América Latina definiu a mudança social como essencial para a fé Católica. Apesar de a Igreja estar promovendo uma grande variedade de esforços populares organizacionais, o sucesso do modelo da Ação Cultural Popular ACPO, de ensino pelo rádio, levou muitas dioceses e grupos católicos a darem prioridade às rádios educativas. Uma pesquisa recente da Associação das Emissoras Católicas da América Latina aponta a existência de cerca de 350 emissoras de rádio locais sob a tutela direta da Igreja Católica, e a maioria possui algum tipo de programação educativa formal ou não-formal.

Muitas dessas estações de rádio educativo começaram com programas de alfabetização básica e matemática simples.

Há uma preocupação emergente, entretanto, de que a alfabetização não é apenas a capacidade de interpretar símbolos escritos, mas sim uma característica funcional daqueles que participam das decisões sociais e do exercício do poder social. Portanto, a educação básica, para tornarse funcional e não rapidamente esquecida, deveria abrir, aos mais pobres, a possibilidade de entrar em organizações que lhes permita participar das decisões locais e nacionais.

A função das rádio-escolas e estações de rádio educativo deixou de ser um canal de informação técnica para a produtividade para tornar-se uma rede de comunicação de organizações populares. Tais redes consistem, tipicamente, em conselhos de desenvolvimento da comunidade, organizações de mulheres, cooperativas e grupos de pressão de trabalhadores rurais e urbanos, todos ligados às federações regionais e nacionais. Um Centro Regional de Treinamento de Lideranças e uma estação de rádio regional servem como o pólo para cada Rede de

10. McANANY, Emile, SCHNITMAN, Jorge e JANUS, Noreene (eds.). Communication and social structure, critical studies in mass media research. (Comunicação e estrutura social, estudos críticos sobre a pesquisa de comunicação de massa) Nova York: Praeger, 1981.

11. BATES,A.Broadcastin in education: an evaluation. (Transmissão educativa: avaliação) London: Constable and Co.Ltd., 1984. JAMISON, Dean T. e McANANY, Emile. Radio for education and development. (Rádio para educação e desenvolvimento) Beverly Hills, CA: Sage Publications Inc., 1978. 
Comunicação Regional. Em muitos países como a Bolívia e a Guatemala, as estações de rádio formaram federações nacionais com a função de uma espécie de agência de notícias alternativa, enviando para cada estação de rádio popular informações que não seriam comumente divulgadas por outros meios. Algumas destas organizações têm ligações com partidos políti$\cos$, mas os diretores de atividades educativas, mais diretamente associados com a Igreja, evitam qualquer tipo de afiliação política. Cerca de 40 das 50 afiliadas da Federação Latino-Americana de Rádio Educativa (ALER) e outras 40 ou 50 estações de rádio da Igreja na América Latina definiram claramente seus objetivos principais: fortalecer a capacidade organizacional dos movimentos populares e promover, a longo prazo, uma mudança sociopolítica.

Normalmente, estas estações educativas realizam um trabalho voltado para a agricultura, saúde e outras formas de educação básica. Isto sempre combinado com os métodos de conscientização de Paulo Freire.

As estações se destacam por serem "participativas". Dão espaço às várias organizações, mantêm reportagens alternativas com informações sobre os acontecimentos locais e promovem expressões culturais e artísticas da região. Algumas das estações são presididas e gerenciadas por organizações populares, com pessoas da Igreja fornecendo algumas orientações.

Muitas das estações medem os resultados de seu trabalho, a longo prazo, em termos do aumento, mesmo que vagaroso, da capacidade organizacional das comunidades. Em épocas de discussões nacionais cruciais sobre justiça social, as estações de rádio pertencentes às Federações se unem em grandes campanhas e sua influência é bem perceptível. Em geral, entretanto, a maioria dos diretores de estações as veêm apenas como um dos fatores num processo sociopolítico complexo.

\section{PERSPECTIVAS}

A partir da descrição acima, deve estar claro que a eficácia dos diferentes usos da transmissão educativa depende muito dos objetivos, das condições particulares de cada projeto educacional, assim como dos critérios ideológicos impostos pelo avaliador. Os diferentes casos ilustram como o uso educacional dos meios de comunicação, muitas vezes, inspiraram adaptações muito criativas. Algumas das circunstâncias são únicas, mas a experiência acumulada sugere diversificadas direções para se alcançar a eficácia.

\section{Pacote multimídia}

A primeira destas direções é que o ensino veiculado geralmente prova ser mais eficaz quando é parte de um pacote multimídia. Tal pacote pode incluir combinações variadas de textos impressos, orientação direta tanto individual quanto em grupos, fitas de áudio e vídeo, discussões em grupo e uma rede de apoio de organizações comunitárias e familiares. Bates nota que em alguns casos de educação continuada que se utilizam de transmissões simplificadas como único meio - o que pressupõe uma educação básica - devem ser elaboradas como um processo educacional independente e acabado. 
O fato de a transmissão ser parte de uma combinação de mídias significa que a programação deve ser elaborada de forma mutuamente interdependente $e$ que apóie os outros meios.

Os estudantes devem entender como usar as transmissões relacionadas com outras mídias. Por exemplo, se um documentário ajudar os alunos a aplicarem os princípios de um livro às situações do cotidiano, então algum tipo de orientação sobre o uso da transmissão deve ser inserido no próprio programa. Além disso, aqueles que planejam o processo educacional devem estar cientes sobre qual é a contribuição de cada meio para o processo todo e como esta contribuição deve ser elaborada.

\section{Potencial de entretenimento}

A instrução veiculada é mais eficaz na medida em que o potencial de entretenimento das transmissões é melhor explorado. No rádio usa-se o diálogo com muitas vozes, perguntas freqüentes, mudança de ritmo e efeitos sonoros em dramatizações ou a inserção de músicas, tudo isso para explorar a dimensão afetiva do meio. A intimidade transmitida pela voz pode ser capaz de fornecer o apoio emocional necessário para o aprendizado.

Muitos estudos mostraram que as transmissões geralmente superestimam o conhecimento prévio dos ouvintes sobre assuntos gerais e sua habilidade de compreender os princípios mais abstratos, relacionados nas transmissões educativas. Bates cita um estudo anterior de Trenaman (1967) que mostrou que os programas mais concretos eram mais compreensíveis.
A concretude ou a percepção direta das coisas foi introduzida pela personificação e pela dramatização, tomando como objeto as vidas pessoais de indivíduos. $\mathrm{O}$ alto grau de personificação e dramatização melhorou consideravelmente a inteligibilidade dos programas, particularmente para aqueles com menor status educacional e ocupacional. Mesmo idéias muito abstratas podem, geralmente, ser comunicadas para amplos setores da população através de alguns elementos de personificação e dramatização.

\section{Motivação e identificação}

O planejamento e a apresentação do método de ensino a distância que utiliza a transmissão deve ser cuidadosamente baseado na motivação e na identificação dos estudantes. Por exemplo, o programa educativo da Rádio Santa Maria frisava abertamente a importância de seus certificados como instrumento de mobilidade social. Solicitava, também, de seus alunos uma contribuição simbólica para ser dada aos professores auxiliares de campo, para que estes se motivassem a recrutar mais estudantes. Apesar de a RSM ter estabelecido motivações na comunidade como parte do pacote educacional, viu-se que, a menos que os alunos se esforçassem, não haveria processo educacional nenhum. Outros sistemas de rádio-escolas rejeitam essa motivação individualista e insistem no serviço comunitário como principal motivação. Tais avaliações dependem muito de uma análise cuidadosa do contexto cultural dos estudantes.

\section{Treinamento de professores e apoio de campo}

Se a eficácia das transmissões depende dos usos e aplicações que fazem os pro- 
fessores locais dos recursos de que dispõem, então o treinamento destes é essencial. Geralmente, um erro inicial é achar que a eficácia do projeto está na transmissão apenas. $\mathrm{O}$ projeto de ensino de matemática pelo rádio na Nicarágua previu este problema e elaborou o programa de maneira que este dependesse relativamente pouco do professor local. Outras rádio-escolas na América Latina dependiam muito dos monitores locais, e o processo de ensino falhou em muitos lugares porque bons monitores não estavam disponíveis ou não eram bem treinados.

\section{Dedicação ao ensino a distância}

Para fazer da necessidade dos estudantes uma prioridade é importante ter um corpo de professores e uma instituição de transmissão totalmente dedicadas ao ensino a distância. As universidades livres se beneficiaram por estarem associadas com produtores profissionais. No entanto, existem tensões entre as demandas de compromissos dos produtores com o público em geral e as necessidades de um número relativamente pequeno de estudantes. As rádio-escolas na América Latina, apesar de, geralmente, sofrerem com a falta de qualificação profissional, ganham por terem controle sobre o horário nobre de estações de rádio populares, assim como por terem os serviços de uma equipe totalmente dedicada.

Por outro lado, as primeiras campanhas e programas de ensino a distância iniciados por ministérios da educação, estruturadas em termos de métodos de ensino convencionais, mais falharam do que foram bem sucedidas. Projetos recentes, especialmente aqueles com alguma interação entre o estúdio e a sala de aula, por telefone ou rádio, prometem ultrapassar esta dificuldade em algum grau.
Eles também requerem uma orientação do professor local para definir a melhor maneira de firmar, na memória dos estudantes, tanto o conteúdo transmitido quanto aquele dado em sala de aula. Em muitos casos é duvidoso que tal orientação possa ser dada.

\section{Apoio comunitário}

Os programas de ensino não-formal e a distância geralmente se beneficiam por terem o apoio de uma infra-estrutura de organizações locais e comunitárias. $\mathrm{O}$ ensino formal é mantido por sua necessidade social e por sua natureza compulsória. Quase todos os programas bem-sucedidos de ensino não-formal, tal como o programa de inglês na Suécia, devem muito de seu sucesso à promoção e recrutamento das organizações locais.

\section{Preocupação crítica}

Os programas de ensino a distância mais democraticamente concebidos, especialmente aqueles que utilizam as transmissões, têm uma crescente preocupação de crítica social e política. Os produtores de tais programas, em sua maioria, sentem que estariam prestando um desserviço aos seus alunos se não incluíssem este componente - a crítica social e política presente na educação. É importante que os alunos vejam que tanto o ensino quanto a transmissão são opções dentro da estrutura de uma sociedade democrática. Isso vale para a transmissão educativa para crianças, mas tem uma importância ainda maior na transmissão educativa para adultos. Percebendo estes aspectos, poderão obter maior crescimento na sua liberdade pessoal e utilizar o novo conhecimento de maneira criativa. 


\section{Componente de pesquisa}

Quase todas as instituições de ensino a distância eficazes, que utilizam mídias mais modernas, perceberam a importância de se ter um pesquisador acompanhando o desenvolvimento do seu programa educativo. Um ensino utilizando uma combinação de mídias e se comprometendo a responder fle- xivelmente às necessidades é um processo muito mais complicado que o ensino convencional em sala de aula, e são necessárias pesquisas constantes, monitorando os resultados. Equipamentos caros aumentam os riscos financeiros, mas experiências provam que projetos bem elaborados, visando a uma melhor qualidade de ensino para mais pessoas, validam tanto o risco quanto o esforço. 